(2) Open Access Full Text Article

\title{
Assessing the effect of omega-3 fatty acid combined with vitamin D3 versus vitamin D3 alone on estradiol levels: a randomized, placebo-controlled trial in females with vitamin $\mathrm{D}$ deficiency
}

This article was published in the following Dove Medical Press journal: Clinical Pharmacology:Advances and Applications

\author{
Amani H Al-Shaer ${ }^{1}$ \\ Mahmoud S Abu-Samak' \\ Luai Z Hasoun' \\ Beisan A Mohammad ${ }^{1,2}$ \\ Iman A Basheti' \\ 'Department of Clinical Pharmacy \\ and Therapeutics, Applied Science \\ Private University, Amman, Jordan; \\ ${ }^{2}$ Department of Physiological Sciences, \\ Fakeeh College for Medical Sciences, \\ Jeddah, Kingdom of Saudi Arabia
}

\begin{abstract}
Purpose: Outcomes investigating the effect of vitamin D3 (VD3) and omega-3 fatty acids (Omega-3FA) on serum estradiol (E2) are scarce and conflicting. No previous study has investigated the effect of VD3 combination with Omega-3FA on E2 levels. This study was designed to investigate the effect of VD3, Omega-3FA and VD3 plus Omega-3FA on serum E2 levels in premenopausal females diagnosed with vitamin D deficiency (VDD).
\end{abstract}

Subjects and methods: This randomized, placebo-controlled clinical trial was designed to evaluate the effects of 50,000 IU VD3 taken weekly, $300 \mathrm{mg}$ Omega-3FA taken daily and their combination by the study participants for 8 weeks. The mid-follicular serum levels of E2 and 25-hydroxy vitamin D (25OHD) were assessed at 8 weeks. The study was conducted during winter on a convenience sample of healthy premenopausal Jordanian females with diagnosed VDD. Fasting serum levels for 25OHD and E2 were assessed at baseline and the end of the trial (after 8 weeks). Data were entered into SPSS and analyzed.

Results: Healthy premenopausal Jordanian females ( $\mathrm{N}=86)$ with diagnosed VDD, mean age $32.8 \pm 8.9$ years, were recruited into the study. Supplementation of VD3 alone resulted in a significant increase in serum $25 \mathrm{OHD}(13.4 \pm 7.9-28.2 \pm 7.1 \mathrm{ng} / \mathrm{mL}, P<0.001)$ and a significant decrease in E2 levels $(85.7 \pm 16.5-60.3 \pm 20.6 \mathrm{pg} / \mathrm{mL}, P=0.001)$. Omega-3FA intake led to a significant decrease in serum $25 \mathrm{OHD}$ levels $(21.2 \pm 12.8-13.6 \pm 9.2 \mathrm{ng} / \mathrm{mL}, P=0.001)$ and a significant increase in E2 levels $(56.3 \pm 19.2-78.4 \pm 23.7 \mathrm{pg} / \mathrm{mL}, P=0.006)$. Combination therapy (VD3 plus Omega-3FA) resulted in a significant increase in both $25 \mathrm{OHD}(12.0 \pm 4.7-35.1 \pm 9.5$ $\mathrm{ng} / \mathrm{mL}, P<0.001)$ and E2 (43.0 $\pm 23.4-57.3 \pm 31.5 \mathrm{pg} / \mathrm{mL}, P=0.028)$ levels.

Conclusion: Results of this study provide vital insight into the effects of D3, Omega-3FA and a combination of their supplementation on premenopausal Jordanian females with diagnosed VDD. Eight weeks of therapy led to decreased E2 level by VD3 and increased level by Omega-3FA supplementation. With regard to 25OHD, its level was increased by VD3 and decreased by Omega-3FA supplementation. Combination of VD3 plus Omega-3FA increased the levels of both E2 and 25OHD. Trial registration: This trial was registered at clinicaltrials.gov as NCT03333564.

Keywords: vitamin D3, omega-3 fatty acids, serum levels of estradiol, premenopausal females, vitamin D deficiency, cancer

\section{Introduction}

Both vitamin D (VD) and omega-3 fatty acids (Omega-3FA) are important nutrients for the maintenance of people's health. It is well known that VD plays an essential role
Correspondence: Mahmoud S Abu-Samak Department of Clinical Pharmacy and Therapeutics, Applied Science Private University, Al Arab st. 2I,

Amman I1931, Jordan

Tel +96265609999 (ext 1836)

Fax +96265232899

Emailm_abusamak@asu.edu.jo 
in calcium and phosphate $\left(\mathrm{PO}_{4}\right)$ homeostasis, bone formation and other metabolic processes in the human body. ${ }^{1-5}$ With regard to VD deficiency (VDD), it has been a common worldwide long-standing dilemma, linked to many diseases, including rickets in children and osteoporosis in adults. ${ }^{6-8}$ Low VD levels have been associated with increased risk of several diseases, including cancer, infections, autoimmune diseases and cardiovascular diseases (CVDs). ${ }^{9,10}$ On the other hand, Omega-3FA are acknowledged as important nutrients throughout the life cycle. ${ }^{11}$ They are required for visual and cognitive development, prevention of CVDs and for protection against Alzheimer's disease and other types of dementia. ${ }^{12,13}$

Some of the effects of VD and Omega-3FA on the human body might be mediated by estrogen. It is known that VD receptor acts as a transcription factor involved in the production of estradiol (E2) and progesterone. ${ }^{14,15}$ Impaired fertility ${ }^{16}$ and polycystic ovaries syndrome ${ }^{17}$ have been associated with VDD. Moreover, estrogen deficiency and VDD are leading factors in bone loss in elderly people ${ }^{18}$ and osteoporosis in postmenopausal females. ${ }^{19}$ The association between osteoporosis and VDD in females is age dependent and is affected by gonadal sex steroid hormones deficiencies such as estrogen deficiency. ${ }^{20}$ Only a few studies have reported the effect of Omega-3FA on estrogen levels in healthy human females. A randomized clinical trial on healthy postmenopausal females showed that supplementation of Omega-3FA plus moderate exercise resulted in a positive effect on the level of estrogen. ${ }^{21}$ Another study shed light on the potential anticancer role of Omega-3FA through its effect on estrogen signaling by converting the pro-proliferative and prosurvival effects of estrogen to a proapoptotic effect on breast cancer cells. ${ }^{22}$ To gain further understanding of the role of VD and Omega3FA in the human body, the relationship between them and estrogen levels needs to be studied.

Studies evaluating the association between VD and sex hormones in females are inconclusive and contradicting. ${ }^{23}$ In one study, the levels of 25-hydroxy vitamin D (25OHD) positively correlated with testosterone levels, but not with E2 levels. In contrast, another study revealed that the levels of 25OHD are inversely associated with E2 levels. ${ }^{23}$

Considering the above, the aim of this randomized placebo-controlled clinical trial was to evaluate the effects of 50,000 IU VD3 taken weekly, $300 \mathrm{mg}$ Omega-3FA taken daily and their combination, taken for 8 weeks, using a convenience sample of healthy premenopausal Jordanian females with diagnosed VDD. Fasting serum levels of 25OHD and E2 were assessed at baseline and the end of the trial (after 8 weeks).

\section{Subjects and methods Subjects}

A convenience sample of healthy female employees at the Applied Science Private University (ASU) and the relatives of employees were invited to participate into this study. An advertisement post was run over 1 week in all the faculties and other buildings at the university.

This study was approved by the ASU ethics committee for the protection of human subjects (protocol no. DRGS2014-2015-165). The study was conducted in accordance with the Helsinki Declaration. Written informed consent was obtained from all study participants. All participants were informed of the study requirements, benefits and risks from taking the supplementations and their freedom to withdraw from the study at any time.

Inclusion criteria included females in the age range of $22-45$ years with a medical diagnosis of VDD (VD $<30 \mathrm{ng} /$ $\mathrm{mL}) .{ }^{25}$ Age range of participants was selected to avoid the confounding effects of hormonal and behavioral changes associated with the postmenopausal stage (typically happens between 48 and 52 years of age). ${ }^{26}$ Exclusion criteria included females previously diagnosed with chronic diseases, including kidney disease (to avoid the effect of prolonged intake of VD3 on kidney stone formation), ${ }^{27}$ pregnant and breastfeeding females and females using hormonal contraceptives.

Females who met the inclusion criteria were contacted by the research team and requested to attend a baseline meeting where details about their age, body mass index (BMI; $\mathrm{kg} / \mathrm{m}^{2}$ ) and other parameters including $\mathrm{E} 2 \mathrm{pg} / \mathrm{mL})$ mid-follicular, 25OHD ( $\mathrm{ng} / \mathrm{mL})$, parathyroid hormone (PTH; $\mathrm{pg} / \mathrm{mL}$ ), calcium $(\mathrm{mg} / \mathrm{dL}), \mathrm{PO}_{4}(\mathrm{mg} / \mathrm{dL})$, urea $(\mathrm{mg} / \mathrm{dL})$ and alanine aminotransferase (ALT; U/L) were collected.

\section{Study design and intervention}

This randomized, placebo-controlled clinical trial was conducted involving premenopausal females with VDD, randomly allocated following stratified randomization, based on age of the participants (performed by a faculty member not involved in the study). Patients were assigned to one of four groups (Figure 1), each receiving a different type of treatment. Group 1 (control group) patients received no treatment; Group 2 (VD group) patients received 50,000 IU of VD3 once weekly; Group 3 (Omega-3FA group) patients received $1,000 \mathrm{mg}$ of wild salmon and fish oil complex once daily, which contains $300 \mathrm{mg}$ of omega3-FA; Group 4 (VD plus Omega-3FA group) patients received 50,000 IU of VD3 once weekly plus $1,000 \mathrm{mg}$ of wild salmon and fish oil complex, which contains $300 \mathrm{mg}$ of Omega-3FA once daily. 
In the VD plus Omega-3FA group, a 4- to 6-hour time interval was followed between administering the two supplements. In the VD and VD plus Omega-3FA group, VD3 was given in a Hi Dee soft gelatin capsule containing 50,000 IU of VD3, equivalent to $1.25 \mathrm{mg}$ of VD3 (cholecalciferol). The capsules were provided by the United Pharmaceuticals Company (Amman, Jordan). Weekly supplements of VD3 were taken by the patients to facilitate patient adherence, rather than daily supplements.

In the Omega-3FA and VD plus Omega-3FA groups, Omega-3FA complex was provided by Jamieson Laboratories (Toronto, ON, Canada), with each soft gelatin capsule containing 1,000 mg of wild salmon and fish oil complex, equivalent to $300 \mathrm{mg}$ of Omega-3FA (180 mg as eicosapentaenoic acid and $120 \mathrm{mg}$ as docosahexaenoic acid [DHA]). Mobile phone text messages were sent by the research team to remind the patients to take their supplements as per schedule.

Therapeutic doses of VD3 and supplement intake duration were decided by an orthopedic surgeon from Ibn Al-Haytham Hospital (one of the biggest private hospitals in Amman, Jordan), based on each patient's serum 25OHD level and in accordance with the Endocrine Society's Clinical Guidelines for treating VDD in adults. ${ }^{28}$ The doses provided to the patients were safe and within recommended doses. Full-body skin exposure to midday sun for 10-15 minutes during summer was found comparable to ingesting up to $10,000-25,000$ IU of VD3 orally. ${ }^{29}$ Furthermore, similar doses of VD3 to that used in this study were administered over 12 months and did not produce any toxicity. ${ }^{30}$ The DHA dose of 722 $\mathrm{mg}$ /day is physiologically relevant and achievable through diet (equivalent to approximately three servings of fatty fish per week). It is also comparable to doses used in other trials involving children, which investigated the effects of Omega3FA on behavior and learning; ${ }^{31}$ no side effects were reported in children taking a dose of $600 \mathrm{mg}$ DHA/day. ${ }^{32}$

\section{Data collection}

This study was carried out at the Faculty of Pharmacy at ASU (Amman, Jordan) during the winter season, between November 2016 and February 2017. Season of study is important to control the seasonal fluctuations of serum 25OHD levels. ${ }^{33}$ It is known that VD synthesis depends on sunlight. Therefore, VD levels decline during winter months and the lowest levels can be detected, which minimize the fluctuations and variations between people.

At baseline and at the end of the study ( 8 weeks from baseline), anthropometric measurements were recorded for all the participants in the four study groups. Qualified nurses collected fasting venous blood samples at baseline and at follow-up, during the mid-follicular phase (ie, within the first 3 days of menstruation). At this phase, the level of E2 is known to be at its minimum level and changes due to the study intervention would be more accurately detected.

Participants' blood samples were collected in $5 \mathrm{~mL}$ serum tubes with a clot activator (VACUETTE ${ }^{\circledR} Z$ Serum [Sep] Clot Activator; GBO). Following collection, the samples were stored at room temperature for around 45-60 minutes, after which they were centrifuged at 4,000 rpm for 10 minutes. Aliquots of at least $1 \mathrm{~mL}$ of serum were measured into five labeled Eppendorf tubes for the measurement of $25 \mathrm{OHD}$, E2, calcium, serum PTH, $\mathrm{PO}_{4}$, ALT and urea.

All samples were stored at $-20^{\circ} \mathrm{C}$ and then analyzed in the quality-controlled and registered laboratories of Ibn AlHaytham Hospital.

\section{Laboratory analysis \\ Serum 25OHD assay}

Serum 25OHD levels were measured using chemiluminescent immunoassay technology by LIAISON ${ }^{\circledR} 25$ OHD Assay (DiaSorin, Stillwater, MN, USA). Specific antibody to VD was used for coating magnetic particles (solid phase), and VD was linked to an isoluminol derivative. Its lower limit of assay was $\sim 4 \mathrm{ng} / \mathrm{mL}$ and intra- and inter-assay coefficients of variation were $5 \%$ and $8.2 \%$, respectively. The assay has $100 \%$ crossreactivity with both metabolites of $25 \mathrm{OHD}$, namely, $25 \mathrm{OHD}_{2}$ and $25 \mathrm{OHD}_{3}$, and thus measures total serum $25 \mathrm{OHD}$ content. The quality of the method was evaluated using the Vitamin D External Quality Assessment Scheme (Deqas.org, 2017).

\section{Serum E2 assay}

Serum E2 levels were measured during the mid-follicular phase with the Estradiol AccuBind ${ }^{\mathrm{TM}}$ ELISA Microwells Test System (Monobind Inc., Lake Forest, CA, USA) using Rayto RT2100C Microplate reader (Bio-Asia Diagnostics, Beijing, China). Normal range of concentration values in the follicular phase was $9-175 \mathrm{pg} / \mathrm{mL},{ }^{34}$ with median $=48 \mathrm{pg} / \mathrm{mL}$ and sensitivity $=8.2 \mathrm{pg} / \mathrm{mL}$.

\section{Serum PTH assay}

The serum PTH levels were measured using PTH Intact ELISA KIT (DRG International, Springfield Township, NJ, USA) with a Rayto RT2100C Microplate reader. It is a twosite ELISA used for the measurement of PTH. The normal range of PTH is from 9 to $90 \mathrm{pg} / \mathrm{mL}$ for serum. Sensitivity of the test was $1.57 \mathrm{pg} / \mathrm{mL}$, and it is capable of detecting very low concentration levels. 


\section{Serum calcium and $\mathrm{PO}_{4}$}

Serum calcium level was measured using CALCIUMARSENAZO kit (BioSystems, Barcelona, Spain). Calcium in the serum reacted with Arsenazo III, forming a colored complex that is measured using spectrophotometry (RAL Analyzers ClimaPlus, Barcelona, Spain). Normal serum calcium level ranged between 8.6 and $10.3 \mathrm{mg} / \mathrm{dL}$ (detection limit of $0.2 \mathrm{mg} / \mathrm{dL}$ ).

Serum $\mathrm{PO}_{4}$ levels were measured with Phosphorus Phosphomolybdate/ultraviolet kit (BioSystems) using spectrophotometry (RAL Analyzers ClimaPlus, Spain). The reference values for serum $\mathrm{PO}_{4}$ were $2.5-4.5 \mathrm{mg} / \mathrm{dL}$, and the detection limit was $0.13 \mathrm{mg} / \mathrm{dL}$.

\section{Liver function}

ALT was measured using the specific ALT BioSystems kit at $340 \mathrm{~nm}$. Detection limit for ALT was $1.6 \mathrm{U} / \mathrm{L}$, with the normal range up to $65 \mathrm{U} / \mathrm{L}$.

\section{Kidney function}

Serum urea level was measured using the UREA/BUNCOLOR kit (BioSystems). The absorbance was read at 600 $\mathrm{nm}$. The reference value for serum level of urea was 15-39 $\mathrm{mg} / \mathrm{dL}$.

\section{Sample size}

The percentage of eligible female candidates who might refuse to participate in the study or fail to complete the different trial phases was unknown at the beginning of the study; therefore, for sample size calculation, we assumed $95 \%$ confidence and 5\% margin of error. The number of women employees in our university ASU was $\sim 150$. Accordingly, 108 women were required. An extra $10 \%$ of subjects were added to the sample size to compensate for the subjects who would drop out from the study. Furthermore, the total number of participants for this study was in accordance with the number of participants recruited in similar recent randomized controlled trials involving females with VDD. ${ }^{24}$

\section{Statistical analysis}

The statistical analysis was performed using the statistical software package SPSS, version 19.0 for Windows (Chicago, IL, USA). Paired $t$-test was conducted to determine significant differences for each study group, comparing baseline and study follow-up data (before and after the administration of the supplements (VD3, Omega-3FA and VD plus Omega3FA). One-way ANOVA test was used to compare parameters among the four study groups. Post hoc analysis, using Tukey honestly significant difference (HSD) test, was conducted to provide specific comparisons between the different groups. Differences were considered significant at $P<0.05$. Multivariate analysis using stepwise multiple regressions was also conducted to estimate the effect of each studied independent variable (IDV) on 25OHD and E2 level as a dependent variable in women with VDD.

\section{Results}

Out of the 116 participants recruited into the study, 86 females $(74 \%)$ were compliant with study procedure and completed the 8-week intervention period (Figure 1). Reasons for dropping out included failure to comply due to busy academic work schedules $(n=24)$ and poor medication adherence $(n=6)$.

\section{Baseline characteristics of the participants}

Baseline characteristics of the study participants are shown in Table 1. Mean age of the participants $(\mathrm{N}=86)$ was 32.80 \pm 8.95 years. Baseline mean value of serum $250 \mathrm{HD}$ was within the deficiency scale level $(14.5 \pm 8.7 \mathrm{ng} / \mathrm{mL})$ for all study groups. No single participant presented in this study with baseline serum $250 \mathrm{HD}$ higher than $30 \mathrm{ng} / \mathrm{mL}$. The BMI values indicated that participants were mildly overweight (26.2 \pm 4.1 ). Serum calcium and $\mathrm{PO}_{4}$ levels were higher than normal ranges, while other mean values of serum parameters, including E2, for all participants were within normal ranges.

\section{Changes in serum 250HD levels within study groups at baseline and follow-up}

Fasting serum $250 \mathrm{HD}$ levels $<30 \mathrm{ng} / \mathrm{mL}$ were considered as VDD. Except in the control group, results showed significant differences in serum 25OHD in the other three groups ( $P$-values for VD, Omega-3FA and VD plus Omega-3FA groups were $P<0.001, P=0.001$ and $P<0.001$, respectively; Table 2). Eight weeks of treatment with VD or VD plus Omega3-FA increased the levels of 25OHD significantly from $13.4 \pm 7.9$ to $28.3 \pm 7.2 \mathrm{ng} / \mathrm{mL}$ and from $12.0 \pm 4.7$ to $35.1 \pm 9.5$ $\mathrm{ng} / \mathrm{mL}$, respectively. Treatment with Omega-3FA for the same duration decreased 25OHD levels significantly from $21.2 \pm 12.8$ to $13.6 \pm 9.2 \mathrm{ng} / \mathrm{mL}$. Post hoc comparisons using Tukey HSD test indicated that the mean baseline of 25OHD in the Omega-3FA group was significantly different from that of the other groups (control, VD and VD plus Omega-3FA groups; $\left.P^{\mathrm{B}}=0.001\right)$.

At the end of the study, the mean 25OHD for the groups VD and VD plus Omega-3FA were significantly different 


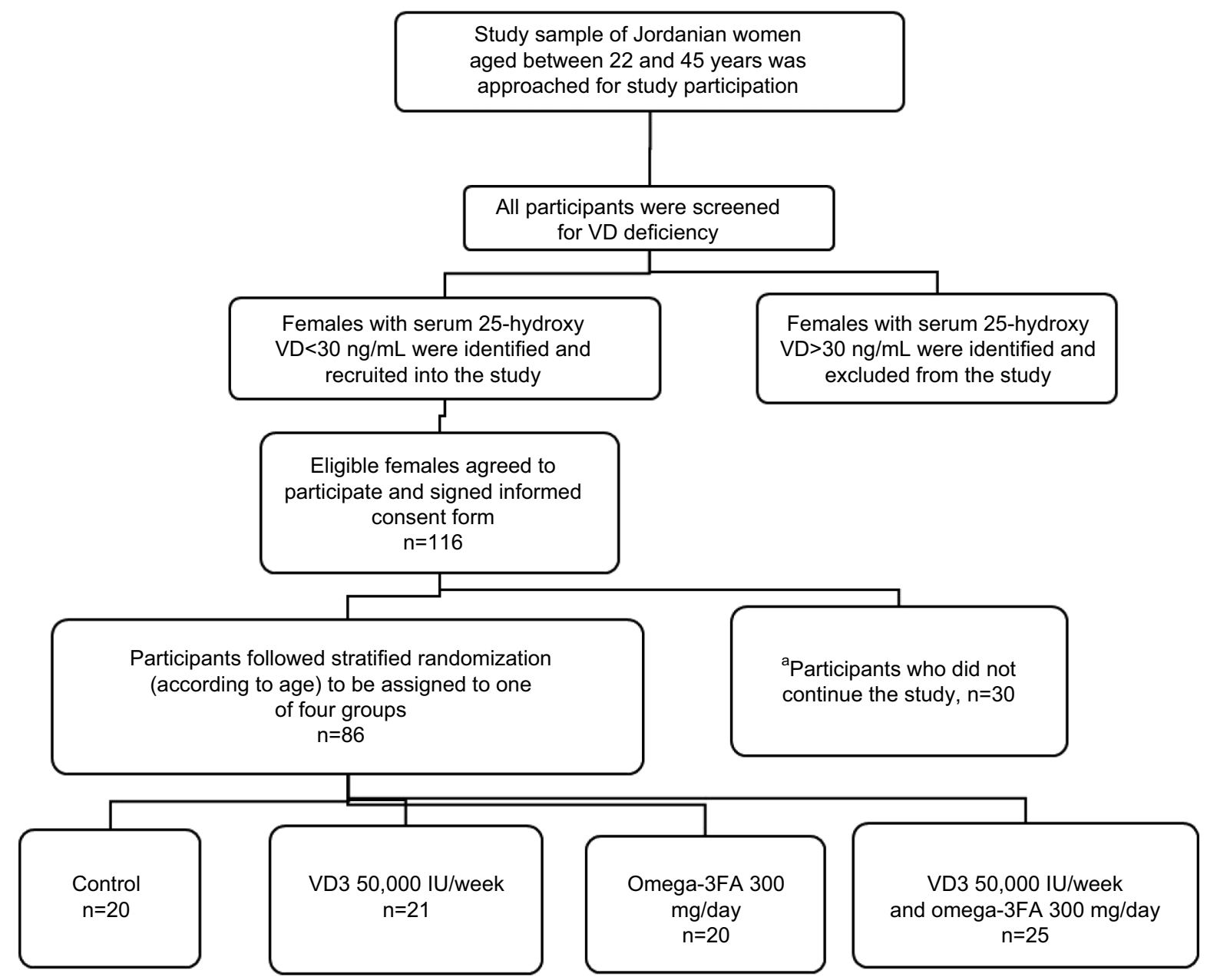

Figure I CONSORT flow diagram for the study, indicating the number of subjects screened, recruited and randomly assigned to the different intervention groups.

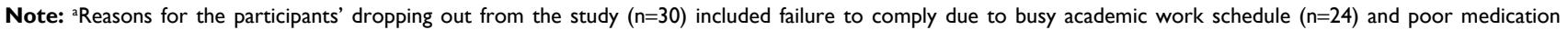
adherence problems $(n=6)$.

Abbreviations: Omega-3FA, omega-3 fatty acid; VD, vitamin D; VD3, vitamin D3; CONSORT, Consolidated Standards of Reporting Trials.

Table I Baseline descriptive statistics of the parameters for all study participants $(\mathrm{N}=86)$

\begin{tabular}{|l|l|l|l|}
\hline Parameter & Mean & SD & Normal range \\
\hline Age (years) & 32.80 & 8.95 & NA \\
BMI $\left(\mathrm{kg} / \mathrm{m}^{2}\right)$ & 26.28 & 4.16 & $18.5-24.9$ \\
E2 $(\mathrm{pg} / \mathrm{mL}) \mathrm{mid}-$ follicular & 66.06 & 29.40 & $9-175$ \\
$25 \mathrm{OHD}(\mathrm{ng} / \mathrm{mL})$ & 14.48 & 8.71 & $30-100$ \\
$\mathrm{PTH}(\mathrm{pg} / \mathrm{mL})$ & 22.89 & 11.05 & $9-90$ \\
Calcium $(\mathrm{mg} / \mathrm{dL})$ & 12.43 & 2.31 & $8.6-10.3$ \\
PO ${ }_{4}(\mathrm{mg} / \mathrm{dL})$ & 4.23 & 0.69 & $2.5-4.5$ \\
Urea $(\mathrm{mg} / \mathrm{dL})$ & 25.56 & 9.09 & $15-39$ \\
ALT $(\mathrm{U} / \mathrm{L})$ & 9.36 & 5.06 & Up to 65 \\
\hline
\end{tabular}

Abbreviations: 25OHD, 25-hydroxy vitamin D; ALT, alanine aminotransferase; BMI, body mass index; E2, serum estradiol; NA, not applicable; $\mathrm{PO}_{4}$, phosphate; PTH, serum parathyroid hormone.

from the control group and the Omega-3FA group. They were also significantly different from each other $\left(P^{\mathrm{C}}<0.001\right)$, as illustrated in Table S1.
Changes in serum E2 levels at midfollicular phase within study groups at baseline and follow-up

With the exception of the control group ( $P=0.358$, paired $t$-test), significant changes in $\mathrm{E} 2$ levels between baseline and follow-up in the other three groups were found. In the VD group, there was a significant decrease in mean E2 levels, which equaled $25.39 \mathrm{pg} / \mathrm{mL}(P=0.001)$. In the Omega-3FA and VD plus Omega-3FA groups, significant increases in the mean E2 levels were detected $(22.088 \mathrm{pg} / \mathrm{mL}, P=0.006$ and $14.225 \mathrm{pg} / \mathrm{mL}, P=0.028$, respectively; Table 3 ).

Based on the one-way ANOVA test results (Table 3), there were significant differences at baseline in the mean E2 levels between all groups $(P \leq 0.001)$. At follow-up, significant changes in $\mathrm{E} 2$ were noted among the study groups $(P \leq 0.001)$. These changes were detected by post hoc comparisons, which 
Table 2 Fasting serum $250 \mathrm{HD}$ at baseline and the end of the study

\begin{tabular}{|l|l|l|l|l|l|}
\hline \multicolumn{5}{|l|}{ Fasting serum 25OHD (ng/mL) } \\
\hline & Control & VD & Omega-3FA & VD plus Omega-3FA group & $P$-value \\
\hline Baseline & $11.97 \pm 4.32$ & $13.42 \pm 7.9$ & $21.2 \pm 12.78$ & $12.01 \pm 4.7$ & $P^{B}=0.001$ \\
Follow-up & $12.73 \pm 5.37$ & $28.25 \pm 7.16$ & $13.58 \pm 9.2$ & $35.14 \pm 9.5$ & $P C<0.001$ \\
Change & -0.76 & -14.82 & 7.62 & -23.12 & \\
$P^{A}$ & 0.29 & $<0.001$ & 0.001 & $<0.001$ & \\
\hline
\end{tabular}

Note: $P^{A}: P$-value for paired $t$-test between baseline and the end of the study for each group; $P^{B}: P$-value for ANOVA with post hoc Tukey HSD done at baseline to compare among all groups; $P$ C: $P$-value for ANOVA with post hoc Tukey HSD done at the end of the study to compare among all groups.

Abbreviations: 25OHD, 25-hydroxy vitamin D; HSD, honestly significant difference; Omega-3FA, omega-3 fatty acid; VD, vitamin D.

Table 3 Serum levels of E2 levels at baseline and follow-up

\begin{tabular}{|l|l|l|l|l|l|}
\hline \multicolumn{5}{|l|}{ Serum E2 mid-follicular phase (pg/mL) } \\
\hline & Control & VD & Omega-3FA & VD plus Omega-3FA group & P-value \\
\hline Baseline & $83.92 \pm 30.94$ & $85.74 \pm 16.5$ & $56.35 \pm 19.2$ & $43.03 \pm 23.4$ & $P=0.000$ \\
Follow-up & $91.44 \pm 28.84$ & $60.34 \pm 20.6$ & $78.43 \pm 23.7$ & $57.25 \pm 31.5$ & $P C=0.000$ \\
Change & -7.52150 & 25.39286 & -22.08750 & -14.22560 & \\
$P^{A}$ & 0.358 & 0.001 & 0.006 & 0.028 & \\
\hline
\end{tabular}

Note: $P^{A}: P$-value for paired $t$-test between baseline and the end of the study for each group; $P$ : $P$-value for ANOVA with post hoc Tukey HSD done at baseline to compare among all groups; $P C$ : $P$-value for ANOVA with post hoc Tukey HSD done at the end of the study to compare among all groups.

Abbreviations: E2, estradiol; HSD, honestly significant difference; Omega-3FA, omega-3 fatty acid; VD, vitamin D.

indicated that at follow-up, the mean scores of E2 in the VD (levels of E2 decreased) and VD plus Omega-3FA (levels of E2 increased) groups were significantly different from those of the control group. While in the Omega-3FA group, the change in E2 was neutral for all groups and there was a significant increase in E2 levels following treatment with Omega-3FA, as stated above (Table S2).

\section{Serum PTH levels at baseline and follow-up}

There were no significant differences in serum PTH levels between baseline and study follow-up in all four groups $(P>0.05)$. One-way ANOVA showed significant differences $(P=0.001)$ in PTH levels at baseline due to randomization and physiological differences among females, while there were no significant differences in PTH levels at the end of the trial (Table 4). Post hoc comparisons indicated that at baseline, the mean score for the group Omega-3FA was significantly higher and different from those of the control and VD plus Omega-3FA groups, while the VD group was neutral with all other groups (Table S3).

\section{Serum calcium levels at baseline and follow-up}

Paired $t$-test between baseline and follow-up for the four groups showed a significant change in calcium levels in the VD and Omega-3FA groups, where the calcium level decreased, and in the VD plus Omega3-FA group, where the calcium level increased (Table 4).

One-way ANOVA showed that at baseline and the study follow-up, there were significant differences among the groups $(P<0.001$ and $P=0.002$, respectively). Post hoc comparisons indicated that baseline calcium in the VD plus Omega3-FA group was significantly lower and different from those of the other groups. On the other hand, levels of calcium in the Omega-3FA group at study follow-up were significantly lower than those of the VD plus Omega3-FA and control groups, while the VD group was neutral with all other groups (Table S4). It should be noted that the levels of calcium at baseline and at the study follow-up in all groups were higher than the normal limit $(8.6-10.3 \mathrm{mg} / \mathrm{dL})$.

\section{Serum $\mathrm{PO}_{4}$ levels within groups at baseline and follow-up}

Only the VD and Omega-3FA groups ( $P=0.028$ and $P=0.02$, respectively) showed a significant decrease in the means of serum $\mathrm{PO}_{4}$ between baseline and study follow-up (Table 4). Post hoc comparisons indicated that at baseline, there were no significant differences among the groups. Nevertheless, at the study follow-up, the mean $\mathrm{PO}_{4}$ level in Omega-3FA group $(P<0.001)$ was significantly different from those of the other groups (Table S5). 


\section{Liver and kidney toxicity (serum ALT and urea)}

There were no significant differences in the means of serum ALT for all study groups, except in the Omega-3FA group, which showed significantly reduced ALT $(P=0.015$, paired $t$-test; Table 5). Moreover, there were no significant differences between basal and study follow-up urea levels in all groups ( $P>0.05$, paired $t$-test; Table 5 ).

\section{Stepwise regression analysis}

Stepwise regression analysis was used to evaluate which IDVs accounted for these associations with 25OHD or E2 in each of the four study groups. Multivariate stepwise regression analysis showed that 25OHD level was a significant independent predictor of $\mathrm{E} 2$ after adjusting for confounding factors $\left(R: 0.452, R^{2}: 0.205 ; P=0.045\right)$. Significant influences of some IDVs on 25OHD levels were also observed as shown in Table 6 . These predictors together explained $\sim 87 \%, 40 \%$, $43 \%$ and $55 \%$ of the variance in $25 \mathrm{OHD}$ levels in the control, VD, Omega-3FA and VD plus Omega-3FA study groups, respectively (Table 6).

\section{Discussion}

The main finding of this novel clinical trial indicated that the combined supplementation of VD3 (50,000 IU weekly dose) and Omega-3FA (300 mg daily dose) significantly increased the serum levels of 25OHD in VD-deficient females, accompanied with maintenance in E2 serum levels. Notable significant reducing effect of Omega-3FA on serum 25OHD levels at the end of the trial $(P=0.001)$ is another important finding of this trial. Multivariate stepwise regression analysis also confirmed the reverse association between serum levels of

Table 4 Serum PTH, calcium and $\mathrm{PO}_{4}$ levels at baseline and follow-up

\begin{tabular}{|c|c|c|c|c|c|}
\hline & Control & VD & Omega-3FA & VD plus Omega-3FA group & $P$-value \\
\hline Serum PTH $(\mathrm{pg} / \mathrm{mL})$ & & & & & \\
\hline Baseline & $17.97 \pm 7.86$ & $26.29 \pm 8.94$ & $29.15 \pm 14.89$ & $18.96 \pm 7.92$ & $P^{B}=0.001$ \\
\hline End of the study & $20.96 \pm 9.94$ & $23.02 \pm 8.18$ & $24.26 \pm 8.31$ & $20.59 \pm 16.49$ & $P C=0.67$ \\
\hline Change & -2.98 & 3.27 & 4.89 & -1.6 & \\
\hline$P^{A}$ & 0.34 & 0.239 & 0.101 & 0.629 & \\
\hline Serum calcium $(\mathrm{mg} / \mathrm{dL})$ & & & & & \\
\hline Baseline & $12.75 \pm 1.0$ & $13.3 \pm 1.4$ & $13.48 \pm 3.2$ & $10.61 \pm 1.6$ & $P^{B}=0.000$ \\
\hline End of the study & $11.98 \pm 1.22$ & $11.28 \pm 1.03$ & $10.43 \pm 1.29$ & $11.69 \pm 1.53$ & $P C=0.002$ \\
\hline Change & 0.763 & 2.01238 & 3.04900 & $-1.07 \mid 2$ & \\
\hline$P^{A}$ & 0.059 & 0.000 & 0.001 & 0.013 & \\
\hline Serum $\mathrm{PO}_{4}(\mathrm{mg} / \mathrm{dL})$ & & & & & \\
\hline Baseline & $4.52 \pm 0.82$ & $4.36 \pm 0.61$ & $4.04 \pm 0.98$ & $4.0 \mathrm{I} \pm 0.37$ & $P^{B}=0.000$ \\
\hline End of the study & 4. $19 \pm 0.48$ & $3.96 \pm 0.38$ & $3.38 \pm 0.5 \mathrm{I}$ & $4.10 \pm 0.80$ & $P C=0.000$ \\
\hline Change & 0.333 & 0.4019 & 0.66 & -0.092 & \\
\hline$P^{A}$ & 0.136 & 0.028 & 0.02 & 0.531 & \\
\hline
\end{tabular}

Note: $P^{A}: P$-value for paired $t$-test between baseline and the end of the study for each group; $P^{B}: P$-value for ANOVA with post hoc Tukey HSD done at baseline to compare among all groups; $P$ : $P$-value for ANOVA with post hoc Tukey HSD done at the end of the study to compare among all groups.

Abbreviations: HSD, honestly significant difference; Omega-3FA, omega-3 fatty acid; $\mathrm{PO}_{4}$, phosphate; PTH, parathyroid hormone; VD, vitamin D.

Table 5 Serum ALT and urea levels at baseline and follow-up

\begin{tabular}{|l|l|l|l|l|}
\hline & Control & VD & Omega-3FA & VD plus Omega-3FA group \\
\hline ALT (U/L) & & & & \\
Baseline & $6.8 \pm 2.9$ & $12.4 \pm 6.2$ & $9.26 \pm 3.8$ & $8.87 \pm 5.0$ \\
Follow-up & $6.3 \pm 3.7$ & $9.5 \pm 5.2$ & $6.5 \pm 2.4$ & $6.97 \pm 3.12$ \\
Change & 0.47 & 2.82 & 2.73 & 1.90 \\
apA & 0.69 & 0.098 & 0.015 & 0.115 \\
Urea (mg/dL) & & & \\
Baseline & $22.8 \pm 4.8$ & $25.09 \pm 13$ & $25.1 \pm 11$ & $28.4 \pm 4.6$ \\
Follow-up & $23.0 \pm 8.7$ & $25.2 \pm 7.9$ & $22.5 \pm 9.9$ & $32.1 \pm 1.5$ \\
Change & -0.17 & -0.109 & 2.62 & -3.7 \\
$P^{A}$ & 0.91 & 0.965 & 0.44 & 0.06 \\
\hline
\end{tabular}

Note: aPA: $P$-value for paired $t$-test.

Abbreviations: Omega-3FA, omega-3 fatty acid; VD, vitamin D. 
Table 6 The multivariate association between the study variables and serum levels of E2 and 25OHD in women with VDD (N=86) using stepwise regression

\begin{tabular}{|c|c|c|c|c|c|c|c|}
\hline \multirow{2}{*}{$\begin{array}{l}\text { Dependent } \\
\text { variable }\end{array}$} & \multirow{2}{*}{$\begin{array}{l}\text { Study } \\
\text { group }\end{array}$} & \multirow{2}{*}{$\begin{array}{l}\begin{array}{l}\text { Univariate effects } \\
\text { estimates }\end{array} \\
\end{array}$} & \multicolumn{5}{|c|}{ Coefficients } \\
\hline & & & B & $F$ & $R$ & $R^{2}$ & $P$-value \\
\hline E2 & Omega-3FA & $25 \mathrm{OHD}$ & 1.168 & 4.634 & 0.452 & 0.205 & 0.045 \\
\hline \multirow[t]{10}{*}{$25 \mathrm{OHD}$} & \multirow[t]{4}{*}{ Control } & CREA_post & -17.930 & 6.039 & 0.501 & 0.251 & 0.004 \\
\hline & & TG_post & -0.067 & 7.217 & 0.678 & 0.459 & 0.027 \\
\hline & & LDL_POST & 0.095 & 11.638 & 0.828 & 0.686 & 0.001 \\
\hline & & Height & 0.351 & 7.217 & 0.873 & 0.763 & 0.043 \\
\hline & \multirow[t]{2}{*}{ VD } & AST_post & -0.749 & 5.371 & 0.469 & 0.220 & 0.018 \\
\hline & & FBG_post & -0.101 & 5.941 & 0.631 & 0.398 & 0.034 \\
\hline & \multirow[t]{2}{*}{ Omega-3FA } & E2_post & 0.197 & \begin{tabular}{|l|}
4.634 \\
\end{tabular} & 0.452 & 0.205 & 0.014 \\
\hline & & BMI_pre & 1.008 & 6.383 & 0.655 & 0.429 & 0.019 \\
\hline & \multirow{2}{*}{$\begin{array}{l}\text { VD plus } \\
\text { Omega-3FA }\end{array}$} & Weight_pre & -0.539 & 12.851 & 0.599 & 0.358 & 0.000 \\
\hline & & ALT_post & -1.352 & 13.364 & 0.741 & 0.549 & 0.006 \\
\hline
\end{tabular}

Note: $\mathrm{B}=$ slope; $F=$ variation between sample means/variation within the samples; $R=$ Pearson linear correlation coefficient; $R^{2}=$ determinant coefficient.

Abbreviations: 25OHD, 25-hydroxy vitamin D; BMI, body mass index; CREA, creatinine; E2, estradiol; FBG, fasting blood glucose; LDL, low-density lipoprotein; Omega3FA, omega-3 fatty acid; TG, triglyceride; VD, vitamin D; VDD, vitamin D deficiency.

$25 \mathrm{OHD}$ and E2 in women with $\operatorname{VDD}\left(R^{2}=0.205\right)$. A recent study has shown a reverse association between $25 \mathrm{OHD}$ and E2 in a trial conducted in 134 women with oligomenorrhea. ${ }^{35}$

In a clinical trial conducted on young females aged between 18 and 22 years, which is a different age group from our study subjects, and with high but normal 25OHD, a similar trend in E2 levels, but to a lesser extent, was shown. ${ }^{36}$ After four weekly doses of 28,000 IU VD3, there was a marginally significant reduction in luteal E2 levels by $3 \%$ per $10 \mathrm{nmol} / \mathrm{L}$ increase of $25 \mathrm{OHD}$, and this may be the mechanism by which VD protects against breast cancer. On the other hand, Zhao et $\mathrm{al}^{23}$ studied the relationship between 25OHD and sex hormones in postmenopausal females in whom E2 levels are normally extremely low; results showed that lower 25OHD was associated with lower E2 levels in females. Another study ${ }^{37}$ showed that VD3 supplementation of 2,000 IU/day for 12 months had no overall effect on reducing E2 levels in overweight postmenopausal females undergoing weight loss program. However, VD repletion was accompanied with greater reductions in E2 levels with a possible dose-dependent effect.

The relation between the two hormones was studied from the opposite side, that is, the effect of $\mathrm{E} 2$ on $25 \mathrm{OHD}$, in females during the whole follicular phase of the menstrual cycle. ${ }^{38}$ The significant change in E2 levels during this phase was not accompanied by any change in the levels of $25 \mathrm{OHD}$ (total, free, bioavailable) and 25OHD binding protein, and they did not have any correlation with E2 during that period of time. Based on this, the assessment of $25 \mathrm{OHD}$ can be done reliably at any point during the follicular phase of the menstrual cycle, and this was another reason to do the measurements in participants during the mid-follicular phase in this study.

A meta-analysis of nine prospective studies on serum 25OHD showed a nonlinear inverse correlation between $25 \mathrm{OHD}$ and breast cancer risk, mainly at $25 \mathrm{OH}$ levels above $35 \mathrm{ng} / \mathrm{mL}$ in postmenopausal women. ${ }^{39}$ It was suggested that VD may inhibit breast cancer through the downregulation of estrogen receptor expression and reduction of estrogen signaling and synthesis. ${ }^{39}$ This suggestion was supported in part by our study results, where VD3 supplementation decreased E2 levels. In addition, in vivo and in vitro studies showed that 1,25 dihydroxy $\operatorname{VD}\left(1,25(\mathrm{OH})_{2} \mathrm{D}\right)$ attenuated the expression of aromatase, an enzyme that stimulates biosynthesis of estrogen from androgen and decreased estrogen signaling in breast cancer cells. ${ }^{40}$ Yet, the reverse happened in cultured ovarian cells, where $1,25(\mathrm{OH})_{2} \mathrm{D}$ was responsible for $9 \%$ of the stimulation of E2 synthesis via VD receptor, which acts as a gene transcriptional factor for aromatase enzyme. ${ }^{15}$ In the liver, however, findings of these studies did not contradict with our data with respect to E2 changes during the mid-follicular phase. Other inconsistent findings shown in previous studies compared to our data may be contributed by the difference in the mean age of the study participants, in addition to the study protocol including the doses and period of intervention. The pathogenesis of age-related bone loss has gained more attention in recent studies. ${ }^{41}$ It seems to begin after age 30 years and around the age of 40 years. $^{20}$ The association between 25OHD and E2 seems to be more obvious in osteoporosis. ${ }^{25} \mathrm{E} 2$ deficiency that occurs after menopause ${ }^{19}$ accelerates loss of bone mass, ${ }^{18}$ 
as a consequence of accelerated bone resorption. ${ }^{19}$ Consequently, VDD decreases calcium absorption, exacerbating osteoporosis. Accordingly, the effects of VD supplementation observed in this trial may play a preventive role against osteoporosis during early life ${ }^{42}$ without any adverse effect on E2 levels. Therefore, the combination may be recommended for improving musculoskeletal outcome. ${ }^{43}$ Modulatory effects for VD supplementation that promote the effect of Omega3FA on serum E2 may depend on VD receptor, which acts as a transcription factor as concluded before. ${ }^{14,15}$

VD is hydroxylated to $250 \mathrm{OD}$ and then converted to the active form, $1,25(\mathrm{OH})_{2} \mathrm{D}$ in the kidney by $1 \alpha$-hydroxylase. ${ }^{44}$ Decreased renal function may suppress $1 \alpha$-hydroxylase activity, which leads to lower levels of $1,25(\mathrm{OH})_{2} \mathrm{D}$ in patients with chronic kidney disease (CKD) ${ }^{45}$ Furthermore, VDD is a known risk factor for CVD in CKD patients. ${ }^{46}$ Therefore, it is necessary to replenish the levels of $1,25(\mathrm{OH})_{2} \mathrm{D}$ in these patients to decrease the risk of CVD, and one strategy to do this is through the use of Omega3FA. An et $\mathrm{al}^{47}$ demonstrated that $1,25(\mathrm{OH})_{2} \mathrm{D}$ significantly increased, with no change in $25 \mathrm{OHD}$ levels, in dialysis patients after 6 months of administration of $2,500 \mathrm{mg}$ Omega-3FA without VD3. This effect of Omega-3FA was hypothesized to be due to either extrarenal $1 \alpha$-hydroxylase stimulation and subsequent activation of VD3 or suppression of the enzyme 24-hydroxylase that catabolizes $1,25(\mathrm{OH})_{2} \mathrm{D}$. In another study that involved eight $\mathrm{CKD}$ patients with insufficient or deficient 25OHD levels and undergoing hemodialysis, 2,000 mg Omega-3FA with VD3 administered for 3 months resulted in an increase (although not significant) in $1,25(\mathrm{OH})_{2} \mathrm{D}$ with a significant increase in $25 \mathrm{OHD}$ levels. The ratio of $1,25(\mathrm{OH})_{2} \mathrm{D}$ to $25 \mathrm{OHD}$, which reflects the activation of $1 \alpha$-hydroxylase, also increased significantly. ${ }^{45}$ In our study groups, we did not measure the serum levels of Omega-3FA and $1,25(\mathrm{OH})_{2} \mathrm{D}$, and this can be considered a limitation. A randomized clinical trial on healthy postmenopausal women revealed that $1,000 \mathrm{mg}$ of Omega-3FA administered daily for 4 months concurrently with moderate intensity exercise increased the levels of estrogen, $1,25(\mathrm{OH})_{2} \mathrm{D}$ and calcitonin and decreased the PTH level. ${ }^{21}$ It was suggested that the increased levels of estrogen were affected by coordinated changes in increased calcitonin and decreased PTH levels that interplayed to allow elevations in estrogen levels. In this study, administration of Omega-3FA to a greater number of participants (a strength point) who were normal young females with VDD caused a significant increase in E2, which could be beneficial for treatment of osteoporosis in postmenopausal females.
Combination of Omega-3FA and VD3 was evaluated for several purposes in different studies. ${ }^{45}$ One of these was the VITAL study, which was a randomized, double-blinded, placebo-controlled trial assessing the effect of 2,000 IU/day of VD3 and 1,000 mg/day of Omega-3FA on the prevention of cancer and CVD among 25,875 men and women aged $50-55$ years. $^{48}$

\section{Conclusion}

To the best of our knowledge, this study is the first to show the effect of the VD plus Omega-3FA group combination on E2 in normal young premenopausal females with VDD. The VD plus Omega-3FA group reversed the decreasing effect of VD alone and Omega-3FA alone on E2 and 25OHD, respectively. The VD plus Omega-3FA group showed a significant increase in both 25OHD and E2 levels without causing disturbances in $\mathrm{PTH}$, calcium and $\mathrm{PO}_{4}$ homeostasis or any kidney or liver toxicity. Based on these findings, it seems that the positive effect of Omega-3FA alone on E2 is not through the suppression of $25 \mathrm{OHD}$, because in its combination with VD3, an increase in both 25OHD and E2 occurred. Using VD plus Omega-3FA can be beneficial for several diseases including, but not limited to, the improvement of bone-related diseases and CVDs, especially CKD. ${ }^{13,49}$ Certainly, further research is required to explore and confirm the beneficial effects of this combination.

\section{Data sharing statement}

The datasets generated and/or analyzed during the current study are available (for 10 years since the study conduct date) from the corresponding author on reasonable request. Any other study-related documents will be provided upon request as well.

\section{Acknowledgment}

The authors are grateful to the Applied Science Private University, Amman, Jordan, for the full financial support granted for this research project (Grant No. DRGS-2014-2015-165).

\section{Author contributions}

AHA, MSA, BAM, LZH and IAB designed the research; AHA conducted the research; LZH and MSA analyzed the data; LZH and MSA wrote the paper; MSA and AHA obtained Institutional Review Board approval and AHA, MSA, LZH, BAM and IAB reviewed the paper. All authors contributed to data analysis, drafting and revising the article, gave final approval of the version to be published, and agree to be accountable for all aspects of the work.

\section{Disclosure}

The authors report no conflicts of interest in this work. 


\section{References}

1. Holick MF. Sunlight and vitamin D for bone health and prevention of autoimmune diseases, cancers, and cardiovascular disease. Am J Clin Nutr. 2004;80(6 Suppl):1678S-1688S.

2. Holick MF. Vitamin D: importance in the prevention of cancers, type 1 diabetes, heart disease, and osteoporosis. Am J Clin Nutr. 2004;79(3):362-371.

3. Zhu K, Oddy WH, Holt P, et al. Tracking of vitamin D status from childhood to early adulthood and its association with peak bone mass. Am J Clin Nutr. 2017;106(1):276-283.

4. Latimer CS, Brewer LD, Searcy JL, et al. Vitamin D prevents cognitive decline and enhances hippocampal synaptic function in aging rats. Proc Natl Acad Sci USA. 2014;111(41):E4359-E4366.

5. Hughes MR, Malloy PJ, Kieback DG, et al. Point mutations in the human vitamin D receptor gene associated with hypocalcemic rickets. Science. 1988;242(4886):1702-1705.

6. Hilger J, Friedel A, Herr R, et al. A systematic review of vitamin D status in populations worldwide. Br J Nutr. 2014;111(1):23-45.

7. Cashman KD, Dowling KG, Škrabáková Z, et al. Vitamin D deficiency in Europe: pandemic? Am J Clin Nutr. 2016;103(4):1033-1044.

8. Morrison NA, Qi JC, Tokita A, et al. Prediction of bone density from vitamin D receptor alleles. Nature. 1994;367(6460):284-287.

9. Holick MF, Chen TC. Vitamin D deficiency: a worldwide problem with health consequences. Am J Clin Nutr. 2008;87(4):1080S-1086S.

10. Ford JA, Maclennan GS, Avenell A, et al. Cardiovascular disease and vitamin D supplementation: trial analysis, systematic review, and metaanalysis. Am J Clin Nutr. 2014;100(3):746-755.

11. Ruxton CH, Reed SC, Simpson MJ, Millington KJ. The health benefits of omega-3 polyunsaturated fatty acids: a review of the evidence. JHum Nutr Diet. 2004;17(5):449-459.

12. Swanson D, Block R, Mousa SA. Omega-3 fatty acids EPA and DHA: health benefits throughout life. Adv Nutr. 2012;3(1):1-7.

13. Lee JH, O'Keefe JH, Lavie CJ, Harris WS. Omega-3 fatty acids: cardiovascular benefits, sources and sustainability. Nat Rev Cardiol. 2009;6(12):753-758.

14. Kinuta K, Tanaka H, Moriwake T, Aya K, Kato S, Seino Y. Vitamin D is an important factor in estrogen biosynthesis of both female and male gonads. Endocrinology. 2000;141(4):1317-1324.

15. Parikh G, Varadinova M, Suwandhi P, et al. Vitamin D regulates steroidogenesis and insulin-like growth factor binding protein-1 (IGFBP-1) production in human ovarian cells. Horm Metab Res. 2010;42(10): 754-757.

16. Grundmann M, von Versen-Höynck F. Vitamin D - roles in women's reproductive health? Reprod Biol Endocrinol. 2011;9(1):146-7827.

17. Velija-Asimi Z. Evaluation of the association of vitamin D deficiency with gonadotropins and sex hormone in obese and nonobese women with polycystic ovary syndrome. Med Glas (Zenica). 2014;11(1):170-176.

18. Drake MT, Clarke BL, Lewiecki EM. The pathophysiology and treatment of osteoporosis. Clin Ther. 2015;37(8):1837-1850.

19. Riggs BL. The mechanisms of estrogen regulation of bone resorption. J Clin Invest. 2000;106(10):1203-1204.

20. Clarke BL, Khosla S. Physiology of bone loss. Radiol Clin North Am. 2010;48(3):483-495.

21. Tartibian B, Hajizadeh Maleki B, Kanaley J, Sadeghi K. Long-term aerobic exercise and omega-3 supplementation modulate osteoporosis through inflammatory mechanisms in post-menopausal women: a randomized, repeated measures study. Nutr Metab (Lond). 2011;8(1):71-1770.

22. Cao W, Ma Z, Rasenick MM, Yeh S, Yu J. N-3 poly-unsaturated fatty acids shift estrogen signaling to inhibit human breast cancer cell growth. PLoS One. 2012;7(12):e52838.

23. Zhao D, Ouyang P, de Boer IH, et al. Serum vitamin D and sex hormones levels in men and women: The Multi-Ethnic Study of Atherosclerosis (MESA). Maturitas. 2017;96:95-102.
24. Smith TJ, Tripkovic L, Damsgaard CT, et al. Estimation of the dietary requirement for vitamin $\mathrm{D}$ in adolescents aged 14-18 y: a dose-response, double-blind, randomized placebo-controlled trial. Am J Clin Nutr. 2016;104(5):1301-1309.

25. Gennari C. Calcium and vitamin D nutrition and bone disease of the elderly. Public Health Nutr. 2001;4(2B):547-559.

26. Morris DH, Jones ME, Schoemaker MJ, Mcfadden E, Ashworth A, Swerdlow AJ. Body mass index, exercise, and other lifestyle factors in relation to age at natural menopause: analyses from the breakthrough generations study. Am J Epidemiol. 2012;175(10):998-1005.

27. Jackson RD, Lacroix AZ, Gass M, et al. Calcium plus vitamin D supplementation and the risk of fractures. N Engl J Med. 2006;354(7): 669-683.

28. Holick MF, Binkley NC, Bischoff-Ferrari HA, et al. Evaluation, treatment, and prevention of vitamin D deficiency: an Endocrine Society clinical practice guideline. J Clin Endocrinol Metab. 2011;96(7): 1911-1930.

29. Holick MF. The vitamin D epidemic and its health consequences. J Nutr. 2005;135(11):2739S-2748.

30. Binkley N, Gemar D, Engelke J, et al. Evaluation of ergocalciferol or cholecalciferol dosing, 1,600 IU daily or 50,000 IU monthly in older adults. J Clin Endocrinol Metab. 2011;96(4):981-988.

31. Bloch MH, Qawasmi A. Omega-3 fatty acid supplementation for the treatment of children with attention-deficit/hyperactivity disorder symptomatology: systematic review and meta-analysis. J Am Acad Child Adolesc Psychiatry. 2011;50(10):991-1000.

32. Richardson AJ, Burton JR, Sewell RP, Spreckelsen TF, Montgomery P. Docosahexaenoic acid for reading, cognition and behavior in children aged 7-9 years: a randomized, controlled trial (the DOLAB Study). PLoS One. 2012;7(9):e43909.

33. Wacker M, Holick MF, Sunlight HMF. Sunlight and Vitamin D: a global perspective for health. Dermatoendocrinol. 2013;5(1):51-108.

34. Santoro N, Worsley R, Miller KK, Parish SJ, Davis SR. Role of estrogens and estrogen-like compounds in female sexual function and dysfunction. J Sex Med. 2016;13(3):305-316.

35. Grzechocinska B, Warzecha D, Szymusik I, Sierdzinski J, Wielgos M. $25(\mathrm{OH}) \mathrm{D}$ serum concentration in women with menstrual disorders - risk factors for vitamin D deficiency. Neuro Endocrinol Lett. 2018;39(3):219-225.

36. Knight JA, Wong J, Blackmore KM, Raboud JM, Vieth R. Vitamin D association with estradiol and progesterone in young women. Cancer Causes Control. 2010;21(3):479-483.

37. Mason C, de Dieu Tapsoba J, Duggan C, et al. Effects of vitamin D supplementation during weight loss on sex hormones in postmenopausal women. Menopause. 2016;23(6):645-652.

38. Franasiak JM, Wang X, Molinaro TA, et al. Free vitamin D does not vary through the follicular phase of the menstrual cycle. Endocrine. 2016;53(1):322-326.

39. Bauer SR, Hankinson SE, Bertone-Johnson ER, Ding EL. Plasma vitamin D levels, menopause, and risk of breast cancer: dose-response meta-analysis of prospective studies. Medicine. 2013;92(3):123-131.

40. Krishnan AV, Swami S, Feldman D. The potential therapeutic benefits of vitamin D in the treatment of estrogen receptor positive breast cancer. Steroids. 2012;77(11):1107-1112.

41. Goldman AL, Donlon CM, Cook NR, et al. VITamin D and OmegA-3 TriaL (VITAL) bone health ancillary study: clinical factors associated with trabecular bone score in women and men. Osteoporos Int. 2018;29(11):2505-2515.

42. Kilınç S, Atay E, Ceran Ö, Atay Z. Evaluation of vitamin D status and its correlation with gonadal function in children at mini-puberty. Clin Endocrinol. 2019;90(1):122-128.

43. Donlon CM, Leboff MS, Chou SH, et al. Baseline characteristics of participants in the VITamin D and OmegA-3 TriaL (VITAL): effects on bone structure and architecture. Contemp Clin Trials. 2018;67:56-67.

44. Deluca HF. Overview of general physiologic features and functions of vitamin D. Am J Clin Nutr. 2004;80(6 Suppl):1689S-1696S. 
45. Lee SM, Son YK, Kim SE, An WS. The effects of omega-3 fatty acid on vitamin D activation in hemodialysis patients: a pilot study. Mar Drugs. 2015;13(2):741-755.

46. Judd SE, Tangpricha V. Vitamin D deficiency and risk for cardiovascular disease. Am J Med Sci. 2009;338(1):40-44.

47. An WS, Lee SM, Son YK, et al. Omega-3 fatty acid supplementation increases 1,25-dihydroxyvitamin D and fetuin-A levels in dialysis patients. Nutr Res. 2012;32(7):495-502.
48. Manson JE, Bassuk SS, Lee IM, et al. The VITamin D and OmegA-3 TriaL (VITAL): rationale and design of a large randomized controlled trial of vitamin D and marine omega-3 fatty acid supplements for the primary prevention of cancer and cardiovascular disease. Contemp Clin Trials. 2012;33(1):159-171.

49. Colston K, Berger U, Coombes RC. Possible role for vitamin D in controlling breast cancer cell proliferation. The Lancet. 1989;333(8631): 188-191. 


\section{Supplementary materials}

Table SI Tukey HSD test for post hoc comparisons of differences in total $25 \mathrm{OHD}$ in all groups at baseline and the end of the study

\begin{tabular}{|l|l|l|l|l|l|}
\hline \multicolumn{3}{|l|}{ Baseline } & \multicolumn{2}{l|}{ End } \\
\hline Group & I & $\mathbf{2}$ & I & $\mathbf{2}$ & $\mathbf{3}$ \\
\hline Control & $\mathrm{II} .97$ & & $\mathrm{I} 2.73$ & & \\
\hline VD & 13.42 & & & 28.25 & \\
\hline Omega-3FA & & 21.20 & $\mathrm{I} 3.58$ & & \\
\hline Combination & $12.0 \mathrm{I}$ & & & & 35.14 \\
\hline Significance & 0.934 & 1.000 & 0.986 & $\mathrm{I} .000$ & 1.000 \\
\hline$P^{\mathrm{B}}=0.00 \mathrm{I}$ & \multicolumn{5}{|l|}{$\mathrm{P}^{\mathrm{C}}=0.000$} \\
\hline
\end{tabular}

Note: $P^{B}=0.00 \mathrm{I}$ : mean difference between column (I) study groups and column (2) study groups at baseline; $P^{C}=0.000$ : mean difference between column ( 1 ) study groups and column (2) study groups at the end of the trial.

Abbreviations: 25OHD, 25-hydroxy vitamin D; HSD, honestly significant difference; Omega-3FA, omega-3 fatty acid; VD, vitamin D.

Table S2 Tukey HSD test for post hoc comparisons of differences in E2 levels in all groups at baseline and the end of the study

\begin{tabular}{|l|l|l|l|l|}
\hline & \multicolumn{2}{l|l}{ Baseline } & \multicolumn{2}{l|}{ End } \\
\hline Group & $\mathbf{I}$ & $\mathbf{2}$ & $\mathbf{I}$ & $\mathbf{2}$ \\
\hline Control & & 83.92 & & 91.44 \\
\hline VD & & 85.74 & 60.34 & \\
\hline Omega-3FA & 56.35 & & 78.43 & 78.43 \\
\hline Combination & 43.03 & & 57.25 & \\
\hline Significance & 0.244 & 0.994 & 0.055 & 0.393 \\
\hline$P^{B}=0.000$ & \multicolumn{5}{l|}{} \\
\hline
\end{tabular}

Note: $P^{B}$ : mean difference between column (I) study groups and column (2) study groups at baseline; $P^{C}$ : mean difference between column (I) study groups and column (2) study groups at the end of the trial.

Abbreviations: E2, estradiol; HSD, honestly significant difference; Omega-3FA, omega-3 fatty acid; VD, vitamin D.

Table S3 Tukey HSD test for post hoc comparisons of differences in PTH levels in all groups at baseline and the end of the study

\begin{tabular}{|l|l|l|l|}
\hline \multicolumn{1}{|l|}{} & \multicolumn{2}{|l|}{ Baseline } & End \\
\hline Group & I & $\mathbf{2}$ & I \\
\hline Control & 17.97 & & 20.96 \\
\hline VD & 26.29 & 26.29 & 23.02 \\
\hline Omega-3FA & & 29.15 & 24.26 \\
\hline Combination & 18.96 & & 20.59 \\
\hline Significance & 0.989 & 0.796 & \\
\hline$P^{B}=0.00$ I & & $P^{C}=0.679$ \\
\hline
\end{tabular}

Note: $P^{B}$ : mean difference between column (I) study groups and column (2) study groups at baseline; $P C$ : mean difference between column (I) study groups and column (2) study groups at the end of the trial.

Abbreviations: HSD, honestly significant difference; Omega-3FA, omega-3 fatty acid; PTH, parathyroid hormone; VD, vitamin D.
Table S4 Tukey HSD test for post hoc comparisons of differences in calcium levels in all groups at baseline and the end of the study

\begin{tabular}{|l|l|l|l|l|}
\hline & \multicolumn{3}{|l|}{ Baseline } & \multicolumn{2}{l|}{ End } \\
\hline Group & I & $\mathbf{2}$ & I & $\mathbf{2}$ \\
\hline Control & & 12.75 & & $\mathrm{II} .98$ \\
\hline VD & & 13.30 & $\mathrm{II} .28$ & $\mathrm{II} .28$ \\
\hline Omega-3FA & & 13.48 & $\mathrm{I} 0.43$ & \\
\hline Combination & $10.6 \mathrm{I}$ & & & $\mathrm{II} .69$ \\
\hline Significance & $\mathrm{I} .000$ & 0.632 & $0.15 \mathrm{I}$ & 0.298 \\
\hline & $\mathrm{P}=0.000$ & $\mathrm{P}^{\mathrm{C}}=0.002$ \\
\hline
\end{tabular}

Abbreviations: HSD, honestly significant difference; Omega-3FA, omega-3 fatty acid; VD, vitamin D.

Table S5 Tukey HSD test for post hoc comparisons of differences in phosphate levels in all groups at baseline and the end of the study

\begin{tabular}{|l|l|l|l|}
\hline & Baseline & \multicolumn{3}{|l|}{ End } \\
\hline Group & I & I & $\mathbf{2}$ \\
\hline Control & 4.52 & 4.19 & \\
\hline VD & 4.36 & 3.96 & \\
\hline Omega-3FA & 4.04 & & 3.38 \\
\hline Combination & 4.01 & 4.10 & \\
\hline Significance & 0.749 & 0.793 & $\mathrm{I} .000$ \\
\hline & $P^{\mathrm{B}}=0.06$ & $\mathrm{P}^{\mathrm{C}}=0.000$ & \\
\hline
\end{tabular}

Abbreviations: HSD, honestly significant difference; Omega-3FA, omega-3 fatty acid; VD, vitamin D. 
Clinical Pharmacology: Advances and Applications is an international, Visit http://www.dovepress.com/testimonials.php to read real quotes peer-reviewed, open access journal publishing original research, reports, from published authors.

reviews and commentaries on all areas of drug experience in humans.

The manuscript management system is completely online and includes a very quick and fair peer-review system, which is all easy to use.

Submit your manuscript here: https://www.dovepress.com/clinical-pharmacology-advances-and-applications-journal 